\title{
O Panóptico no combate à Covid-19
}

\author{
The Panopticon in the fight against Covid-19
}

\section{Vanessa Kiewel Cordeiro*}

\begin{abstract}
Resumo: Propomos o uso do Panóptico como a mais eficaz arma no combate a pandemias. Revisamos a literatura e inovamos aplicando-a ao enfrentamento da Covid-19. Dividimos o Panóptico em dois: o Superpanóptico, em toda a sociedade, e o Pós Panóptico Tecnológico, dentro dos hospitais. Sendo, o primeiro, um sistema de vigilância baseado na alta tecnologia que perpassa a tudo e a todos, a todo tempo. E, o segundo, os locais físicos que melhor reproduzem a lógica do Panóptico na contemporaneidade. Da pesquisa de notícias, concluímos que o Panóptico está mais vivo do que nunca e que as nossas propostas teóricas refletem o que já está em funcionamento, tanto na sociedade, quanto nos hospitais. E que seu uso é altamente eficaz porque reduz o número de novas infecções, garante a maior segurança possível a todos, com grande redução de custos e, principalmente, de perdas humanas.
\end{abstract}

Palavras-chave: Panóptico; Pandemias; Covid-19; Superpanóptico; Pós Panóptico Tecnológico

\begin{abstract}
We propose the use of the Panopticon as the most effective weapon in the fight against pandemics. We reviewed the literature and innovated by applying it to confront Covid-19. We divided the Panopticon in two: the Superpanopticon, in society as a whole, and the Technological Post Panopticon, within hospitals. The first being a surveillance system based on high technology that permeates everything and everyone, at all times. And, the second, the physical locations that best reproduce the logic of the Panopticon in contemporary times. From the news survey, we concluded that the Panopticon is more alive than ever and that our theoretical proposals reflect what is already working, both in society and in hospitals. And that its use is highly effective because it reduces the number of new infections, guarantees the greatest possible safety for everyone, with great cost reduction and, mainly, of human losses.
\end{abstract}

Keywords: Panopticon; Pandemics; Covid-19; Superpanoptic; Technological Post Panopticon

Propomos, neste artigo, a utilização do Panóptico, atualizado e ampliado, por meio das inúmeras tecnologias contemporâneas, como forma de dar maior eficácia e segurança ao enfrentamento da Covid-19, tanto para a população em geral, quanto para os profissionais da saúde e da segurança.

Isso deve ser feito tanto no nível macro, na sociedade em geral, por meio do Superpanóptico, quanto no nível micro, nos hospitais, por meio do Pós Panóptico Tecnológico.

Ora, se já vivemos numa sociedade de "ultra controle"1, sendo vigiados $24 \mathrm{hs}$ por dia, 7 dias por semana, na rua, no trabalho e em casa, se já abrimos mão de toda e qualquer possibilidade de controle dos nossos dados e informações na internet, e isso é um processo sem volta, como afirma Scott McNealy, presidente da Sun Microsystems: "Você já tem privacidade zero. Acostume-se com isso"2 . Por que, então, ao invés de temer o sistema de hipervigilância, não olhamos para as inúmeras possibilidades positivas que dele advêm e não as usamos a nosso favor no enfrentamento dessa pandemia histórica?

Afinal, a tecnologia, em si, não é boa ou má, tudo depende do uso que se faz dela, conforme bem diz Bauman: "São os usos que nós [...] fazemos dessas ofertas que as tornam, assim como seu impacto em nossa vida, boas ou más, benéficas ou prejudiciais" 3 .

Para isso, analisaremos a obra de Foucault e seus elementos centrais no que tange ao Panóptico de Jeremy Bentham, tratando de temas como sociedade disciplinar, poder e controle, bem

\footnotetext{
1 Termo nosso.

${ }^{2}$ MCNEALY apud BOYNE, Post-panopticism, 297.

${ }^{3}$ LYON; BAUMAN, A vigilância líquida como pós-pan-panóptico, In: Vigilância líquida, 22-23.
} 
como as ampliações e alterações propostas a este conceito, em meio à novíssima sociedade da informação e da vigilância eletrônica ininterrupta.

Ao que, já se adianta que, aqui, sustentamos que o Panóptico está mais vivo do que nunca, perpassando e permeando toda a sociedade pós-moderna com suas tecnologias cada vez mais avançadas no campo da informação, da coleta de dados e da vigilância, como bem destaca Zimmer nos resultados de sua tese: "O Panóptico [...] continua sendo válido e atual, por sua onipresença mediada pela Tecnologia da Informação, [...] permanecendo como elemento central nos estudos sobre vigilância eletrônica"4.

E, mais do que isso, defendemos o uso do Superpanóptico e do Pós Panóptico Tecnológico como nossos grandes trunfos e armas mais eficazes no combate às pandemias, como a da Covid-19, que hoje ameaça a humanidade como um todo e o mundo como o conhecemos.

Adentrando, sem mais delongas, ao tema, cabe explicitar, afinal, do que se trata o Panóptico de Bentham e Foucault.

Foucault demonstra a alteração de uma sociedade punitiva, que precisava utilizar sanções extremas ao corpo daqueles que infringiam as normas dos governos monárquicos, sempre de maneira pública e espetacular, como os enforcamentos em praça pública, para, assim, manter o controle sobre o povo que, pelo exemplo bárbaro, aprendia a jamais contrariar os ditames do rei; para uma sociedade disciplinar, que buscava tornar os corpos dóceis e úteis por meio de uma vigilância constante, ou, pelo menos, pela forte impressão de estar-se sendo vigiado a todo tempo ${ }^{5}$.

E, para efetivar esse poder disciplinar, Foucault apresenta o Panóptico de Jeremy Bentham, não apenas como forma arquitetônica ideal para vários tipos de vigilância, mas também como uma metáfora da vigilância que já "estava", como ele frisava, em todo lugar e fazia parte de tudo, já em meados da década de 70 do século passado, quando da publicação de seu icônico livro "Vigiar e Punir"6.

O Panóptico (do grego, olho que tudo vê) foi criado pelo filósofo inglês Jeremy Bentham, no final do século XVIII, como um edifício ideal para os mais diferentes fins que necessitassem de uma vigilância constante, ou aparentemente constante. Em especial, foi criado como a prisão ideal. Porém, o próprio Bentham já indicava seu uso, também, para indústrias, escolas, hospitais, dentre outros. Aqui, destacamos seu uso para hospitais, que é um dos focos deste artigo - ao qual, transportado para o século XXI, optamos por denominar Pós Panóptico Tecnológico -, que seria, e hoje o é, de grande proveito, como o próprio Bentham já preconizava:

Aqui, o médico e o boticário podem saber com certeza que a receita que um prescreveu e o outro executou foi administrada no tempo certo e na maneira exata assim prescritos. Aqui, o cirurgião estará seguro de que suas instruções e ordens foram seguidas em todos os pontos ${ }^{7}$.

O prédio do Panóptico de Bentham seria construído de forma circular, com celas ou salas individuais em seu perímetro, todas elas com grandes janelas voltadas para o centro, onde se encontraria uma torre central de vigilância, também com janelas voltadas para cada uma das celas e, nelas, uma forte luz permanentemente ligada que impedia os vigiados de verem se havia, a cada momento, alguém a vigia-los ou não. Assim, achariam-se perenemente vigiados e, com isso, introjetariam em si tal vigilância, passando a se auto vigiar. O que, em suma, reduziria ao mínimo os custos com a vigilância e maximizaria os resultados de forma praticamente automática ${ }^{8}$.

Este projeto arquitetônico, como foi concebido, jamais foi posto em prática. No entanto, se tornou o paradigma de excelência em vigilância pelos séculos a seguir e, até hoje, como podemos denotar nas atuais prisões de segurança máxima americanas, ou Supermax ${ }^{9}$, que, por meio do uso da

\footnotetext{
${ }^{4}$ ZIMMER, O panóptico está superado?: estudo etnográfico sobre a vigilância eletrônica, 6.

${ }^{5}$ FOUCAULT, O panopticismo. In:Vigiar e punir: nascimento da prisão.

${ }^{6}$ FOUCAULT, Vigiar e punir: nascimento da prisão.

${ }^{7}$ BENTHAM. et al, O panóptico, 70-71. (grifos do original).

${ }^{8}$ Idem, 20-30.

${ }^{9}$ HURLEY, Supermax prison.
} 
mais alta e pós-moderna tecnologia de informática, informação e vigilância, se tornaram o melhor exemplo do Pós Panóptico Tecnológico - termo que usamos para designar os locais físicos fechados que melhor reproduzam a lógica do Panóptico na contemporaneidade.

Todavia, Bentham e Foucault jamais poderiam imaginar a grande transformação tecnológica que vivemos atualmente, numa sociedade dominada pelo Big Data, o infinito banco de dados que, alimentado de boa vontade pelos próprios usuários da internet (ou por falta de opção), se tornou o "olho que tudo vê", ou seja, o Panóptico em si, hoje expandido por tudo e todos, com seus inúmeros "tentáculos" tecnológicos representados pelas TIC's ${ }^{10}$, a internet, a $\operatorname{IoT}^{11}$, a Inteligência Artificial $\left(\mathrm{AI}^{12}\right)$, a indústria 4.0, as câmeras e drones de segurança, a biometria, os chips de identificação nos celulares, cartões de crédito e documentos, e muito mais além.

Por isso, o Panopticismo de Foucault foi revisto e ampliado pela literatura para, assim, verse adequado às inovações tecnológicas contemporâneas, conforme se depreende da fala de Souza \& Oliveira:

Foucault ilumina as conexões entre o Panóptico e a modernidade, [...] e a prática disciplinar rompe as barreiras dos espaços confinados ao que, anteriormente, estava restrita a figura do panóptico, para adotar uma nova roupagem: a vigilância eletrônica, na qual os detalhes pessoais da vida dos indivíduos passam a circular fora no seu controle para dentro de bancos de dados remotos e automatizados que representam uma espécie de versão "ciberespacial" do Panóptico [...]. Assim, vivemos na sociedade de controle, movidos pela difusão da tecnologia que nos insere na sociedade da informação ${ }^{13}$.

Tudo isso fez a sociedade disciplinar foucaultiana ${ }^{14}$ ver-se invadida por uma novíssima sociedade que está nascendo, a sociedade do controle ${ }^{15}$. Porém, como alteração histórico-social que é, esta nova sociedade do controle não se separa automaticamente da sociedade disciplinar. Ambas convivem num período intermediário, no qual a disciplina hierárquica vertical dentro das organizações e espaços físicos coexiste com o controle horizontal difuso na sociedade em geral. O foco destas duas sociedades é o mesmo, a vigilância constante dos indivíduos, tendo como diferenças, apenas, os meios que utilizam para isso. Os bancos de dados automatizados estão para a sociedade de controle, na qual vivemos, como o projeto arquitetônico do Panóptico estava para a sociedade disciplinar ${ }^{16}$.

A partir disso, que é uma revisão muitíssimo rápida e condensada da literatura relativa ao Panóptico e às sociedades disciplinar e de controle, desde os dias de Foucault até os dias atuais da Vigilância Líquida ${ }^{17}$ de Bauman, com seu Sinóptico ou Pós-Pan-Panóptico, passamos à nossa proposta.

Ousamos, aqui, inovar tais leituras para cumprir o desafio de trazer à luz uma forma eficaz de enfrentamento da atual pandemia de Covid-19. Tal inovação, ainda que, academicamente, seja muito preliminar e apressada, pode, para o mundo concreto, ser uma alternativa palpável e possível de ser posta em prática imediatamente, face à urgência urgentíssima que nos impõem os fatos.

Pois bem, a solução que propomos nada mais é do que usar o Superpanóptico, no nível macro, em toda a sociedade, e o Pós Panóptico Tecnológico, no nível micro, dentro de cada um dos hospitais, por meio de suas inúmeras possibilidades positivas, como armas nessa guerra contra o Covid-19.

\footnotetext{
${ }^{10}$ Tecnologias da Informação e Comunicação.

${ }^{11}$ Internet of Things ou Internet das Coisas.

${ }^{12}$ Artificial Intelligence.

13 SOUSA; OLIVEIRA, Banco de dados automatizados: a versão “ciberespacial” do panóptico na sociedade de controle, 625.

${ }^{14}$ FOUCAULT, $O$ panopticismo. In:Vigiar e punir: nascimento da prisão.

${ }^{15}$ DELEUZE, Post-scriptum sobre as sociedades de controle, 219-226.

16 SOUSA; OLIVEIRA, Banco de dados automatizados: a versão "ciberespacial” do panóptico na sociedade de controle, 634.

${ }^{17}$ LYON; BAUMAN, A vigilância líquida como pós-pan-panóptico, In: Vigilância líquida, 40-54.
} 
O termo Superpanóptico, tomamos emprestado de Poster, que diz que vivemos hoje num Superpanóptico por termos todos os nossos dados e atos vigiados e registrados pelas bases de dados, o Big Data, não tendo, todavia, os limites físicos do Panóptico, eis que a vigilância não depende mais de qualquer tipo especial de arquitetura, ocorrendo a todo tempo e em todo lugar, como parte inerente e constitutiva da vida normal e quotidiana dos indivíduos ${ }^{18}$.

E, sim, sabemos das críticas ao caráter invasivo destas tecnologias, em especial, do risco de perder-se por completo o direito à privacidade. Todavia, esta é uma discussão que não cabe aqui. Preferimos, neste momento de grave crise sanitária mundial, focar nos seus usos positivos. Pois, ainda que, com eles, haja alguma violação de privacidade, consideramos que este é um preço baixo a se pagar para garantir os direitos humanos fundamentais à vida e à saúde.

É evidente que o "ultra controle" ${ }^{19}$ do Superpanóptico em que vivemos atualmente pode nos ajudar, e muito, no combate à Covid-19 e a quaisquer outras pandemias que possam sobrevir no futuro. Esse é o papel positivo, por exemplo, do Big Data, que, ao analisar um infindável volume de dados e convertê-los em conhecimento, inovação e valor - ou seja, criar novas ideias - traz consigo um grande avanço para todos os setores da sociedade, inclusive para a área da saúde ${ }^{20}$.

E, disso, já temos inúmeras evidências concretas: desde projetos de cooperação internacional virtual de médicos e outros cientistas na busca de desenvolver remédios e vacinas capazes de aplacar o novo coronavírus, inclusive uma delas sendo conduzida pela própria $\mathrm{OMS}^{21,22}$; passando pela flexibilização, simplificação e agilização de normas da Anvisa ${ }^{23}$ para a fabricação de ventiladores pulmonares artificiais para UTI's ${ }^{24}$, e sua fabricação por indústrias de outras áreas ${ }^{25}$, bem como a criação, por faculdades, de novos, mais simples e baratos tipos de respiradores ${ }^{26}$; até o uso de drones e outros mecanismos tecnológicos, ligados à Internet das Coisas (IoT), na desinfecção de locais públicos ${ }^{27}$; a geolocalização por sinal de telefonia celular e GPS ${ }^{28}$ para controlar aglomerações ${ }^{29}$ e, com a sua detecção, o envio de drones equipados não só com câmeras, mas também com auto falantes e, até, sensores de temperatura corporal ${ }^{30}$, por meio dos quais as autoridades da segurança pública podem dispersar tais aglomerações, utilizar softwares de reconhecimento facial capazes, até, de reconhecer pessoas usando máscaras cirúrgicas ${ }^{31}$, para identificar e multar ou sancionar aqueles que desrespeitam o isolamento social, e, também, verificar se há cidadãos com febre e outros sintomas da Covid-19 circulando nas ruas e encaminhá-los, imediatamente, ao serviço médico mais próximo, podendo, inclusive, fazê-lo coercitivamente, com o envio de viaturas policiais e/ou ambulâncias; não esquecendo dos simples sistemas de tele entrega, que agora estão se estendendo para as mais variadas áreas do comércio; do tele trabalho, que hoje se tornou a regra, não mais a exceção; e das infinitas possibilidades de aulas virtuais, que têm sido oferecidas de forma gratuita, neste momento, numa demonstração de solidariedade ${ }^{32}$.

Esse é o Superpanóptico agindo no combate direto à pandemia, ao qual saudamos, e incentivamos que suas tecnologias sejam, cada vez mais, criadas de forma inovadora e cooperativa, nessa belíssima união de esforços entre todas as nações - coisa jamais vista -, e disseminadas para todos os cantos do mundo, para que possamos, juntos, ainda que distantes, vencer a guerra contra a

\footnotetext{
18 POSTER, The mode of information and postmodernity, In: The second media age, 69.

19 Termo nosso.

20 SOUSA; OLIVEIRA, Banco de dados automatizados: a versão "ciberespacial” do panóptico na sociedade de controle, 631.

${ }^{21}$ Organização Mundial da Saúde (OMS) ou World Health Organization (WHO).

22 WHO, Public statement for collaboration on Covid-19 vaccine development.

23 Agência Nacional de Vigilância Sanitária (Anvisa).

${ }^{24}$ ASCOM/ANVISA, Ventiladores pulmonares: Brasil amplia a produção.

${ }^{25}$ FORBES, Ford se une a $3 M$ e GE para acelerar produção de ventiladores e máscaras.

${ }^{26}$ SOARES, USP projeta ventilador pulmonar de baixo custo e rápida fabricação.

${ }^{27}$ AMARAL, Porto Alegre já pode ter drones para desinfecção de espaços.

${ }^{28}$ Global positioning system ou sistema de posicionamento global.

${ }^{29}$ JORNAL VS, Geolocalização é ferramenta eficaz para monitorar aglomerações durante pandemia.

${ }^{30}$ CASTRO, Drone que mede temperatura corporal a distância reforça combate ao novo coronavírus

${ }^{31}$ PILAGALLO, Coronavírus: veja as tecnologias usadas para combater a pandemia.

${ }^{32}$ Que, porém, não deixam de ser uma ótima estratégia de marketing para um futuro próximo.
} 
Covid-19. E, mais do que isso, criar um novo mundo no qual todas essas soluções tecnológicas positivas permaneçam como prevenção a novas pandemias possíveis, minimizando os riscos e custos, principalmente as perdas humanas, e maximizando os resultados.

No nível macro, portanto, já estamos num bom caminho. A dúvida, no entanto, persiste no nível micro, dentro dos hospitais que estão fazendo o enfrentamento direto à Covid-19. Afinal, não sabemos exatamente como é realizada sua gestão, principalmente no tocante à prevenção do contágio do coronavírus dentre os pacientes e os profissionais da saúde.

O Pós Panóptico Tecnológico que propomos seja implantado nos hospitais é um projeto de vigilância constante dos pacientes à distância, sem contato com nenhum ser humano, contando com toda a tecnologia hoje disponível para tanto, de forma a levar a uma maior eficácia no atendimento aos pacientes, com grande redução de riscos de infecção hospitalar, com a maior proteção possível aos profissionais da saúde, que se manterão sãos e poderão desempenhar seu papel vital em segurança, e com redução no número de funcionários em proporção ao número de pacientes, o que gerará grande economia de recursos e tornará economicamente viável a implantação de todo o sistema de tecnologia de ponta na gestão hospitalar. A mesma lógica também se aplica aos demais locais de atendimento em saúde (UBS's ${ }^{33}$, UPA's ${ }^{34}$, clínicas particulares, etc).

E, em meio à atual pandemia de coronavírus, já estão surgindo iniciativas nesse sentido. É o que podemos depreender - e aplaudir - das seguintes notícias: o desenvolvimento de robôs para cuidar de pacientes em quarentena com sintomas da Covid-19, eles medem a temperatura dos pacientes, entregam refeições, desinfetam as instalações e permitem que os médicos leiam os registros dos pacientes remotamente ${ }^{35}$; a criação de uma cápsula inflável com sistema de filtro de ar para o transporte de pacientes infectados pelo coronavírus, e demais agentes contagiosos, sem pôr em risco equipes de emergência e outros profissionais da saúde ${ }^{36}$; a criação de uma nova ferramenta médica capaz de prever, com $80 \%$ de precisão, quais pacientes infectados podem ter maiores complicações ${ }^{37}$; o desenvolvimento de uma inteligência artificial capaz de detectar a infecção pelo coronavírus em apenas 20 segundos, por meio da análise de tomografias computadorizadas do tórax dos pacientes, com precisão de $96 \%^{38}$; o uso de robôs de telepresença, em hospitais, que realizam a triagem dos pacientes, permitindo que uma enfermeira, à distância, consiga bem encaminhar os pacientes, outros destes robôs são usados nas UTI's, enfermarias e, especialmente, junto aos pacientes em isolamento, possibilitando não apenas consultas remotas entre os pacientes e as equipes médicas, mas, também, que tais pacientes possam receber visitas remotas de seus familiares e, ainda, estes robôs também permitem que médicos afastados, em isolamento domiciliar, possam participar de reuniões clínicas e discussões de $\operatorname{casos}^{39}$; e, a informação, dada pelo CETIC ${ }^{40}$, de que 91\% dos hospitais do Brasil têm acesso à internet e que, parte deles, a utiliza em prontuários eletrônicos e gestão hospitalar, com o fim de possibilitar o resgate rápido dos dados pregressos dos pacientes, bem como o seguimento linear de seu acompanhamento, por qualquer profissional de seu quadro clínico, frisando que as informações necessárias devem estar sempre a um clique de distância ${ }^{41}$.

Portanto, concluímos, primeiramente, que o Superpanóptico, em nível macro, e o Pós Panóptico Tecnológico, no nível micro, são modelos ampliados e atualizados do Panóptico de Foucault e Bentham que, por meio deles e suas múltiplas tecnologias de ponta, está mais vivo do que nunca, perpassando e permeando todos os âmbitos da sociedade.

E, posteriormente, que a sua implantação e incremento na sociedade em geral e nos hospitais são meios altamente eficazes de combater esta pandemia global de coronavírus e de prevenir outras

\footnotetext{
${ }^{33}$ Unidades Básicas de Saúde, os antigos Postos de Saúde.

${ }^{34}$ Unidades de Pronto Atendimento.

${ }^{35}$ PILAGALLO, Coronavírus: veja as tecnologias usadas para combater a pandemia.

${ }^{36}$ Idem.

${ }^{37}$ ROCHA; PEREIRA, Tecnologia contra coronavírus prevê quais infectados terão complicações.

${ }^{38}$ PINHEIRO, Coronavírus: como a tecnologia é usada para combater a pandemia.

${ }^{39} \mathrm{HC}$ ON LINE, Covid-19: HCFMUSP recebe robôs de telepresença para atendimento em casos de isolamento.

${ }^{40}$ Centro de Estudos sobre as Tecnologias da Informação e Comunicação.

${ }^{41}$ MACEDO, O desafio da Medicina high-tech: saúde na palma da mão?
} 
que possam sobrevir no futuro, pois minimizam os custos e riscos, principalmente as perdas humanas, e maximizam os resultados. Aliás, comprovamos que os nossos sugeridos modelos de Superpanóptico e Pós Panóptico Tecnológico não são apenas propostas teóricas, mas, sim, uma constatação do que já está em pleno funcionamento na contemporaneidade.

Saudamos, então, à ideia visionária do Panóptico de Bentham e Foucault, e, também, a todos aqueles que, sabidamente ou não, tornaram-na realidade. Principalmente, aqui, no que nos concerne, na criação e implantação das mais diversas tecnologias que, hoje, são essenciais na guerra contra a pandemia de Covid-19.

Que venham, mais e mais, belas iniciativas, em cooperação científica virtual internacional, para a criação e implantação de novas tecnologias para o bem de toda a humanidade!

\section{Referências}

AMARAL, E. Porto Alegre já pode ter drones para desinfecção de espaços. Correio do Povo, 16 abr. 2020. Disponível em: <https://www.correiodopovo.com.br/not\%C3\%ADcias/geral/portoalegre-j\%C3\%A1-pode-ter-drones-para-desinfec\%C3\%A7\%C3\%A3o-de-espa\%C3\%A7os1.413277>. Acesso em: 22 abr. 2020.

ASCOM/ANVISA. Ventiladores pulmonares: Brasil amplia a produção. 13 abr. 2020. Disponível em: <http://portal.anvisa.gov.br/noticias/-/asset_publisher/FXrpx9qY7FbU/content/ventiladorespulmonares-brasil-ampliando-a-producao/219201>. Acesso em: 22 abr. 2020.

BENTHAM, J. et al. O panóptico. Org. Tomaz Tadeu. Trad. Guacira Lopes Louro, M. D. Magno, Tomaz Tadeu. 2. ed. Belo Horizonte: Autêntica, 2008. Disponível em: < https://docero.com.br/doc/xescv>. Acesso em: 08 abr. 2020.

BOYNE, R. Post-panopticism. In: Economy and Society Journal. V. 29. I. 2, p. 285-307, 2000. Disponível em: <https://www.tandfonline.com/doi/abs/10.1080/030851400360505>. Acesso em: 13 abr. 2020.

CASTRO, B. Drone que mede temperatura corporal a distância reforça combate ao novo coronavírus. $\quad 06$ abr. 2020 . Disponível em: <https://g1.globo.com/pe/pernambuco/noticia/2020/04/06/drone-que-mede-temperatura-corporal-adistancia-reforca-combate-ao-novo-coronavirus-em-pe.ghtml>. Acesso em: 22 abr. 2020.

DELEUZE, G. Post-scriptum sobre as sociedades de controle. In: Conversações. Trad. de Peter Pál Pelbart. Rio de Janeiro: Ed. 34, 1992. Disponível em: < https://grupodeestudosdeleuze.files.wordpress.com/2016/05/deleuze-g-conversac3a7c3b5es.pdf>. Acesso em: 08 abr. 2020.

FORBES. Ford se une a $3 M$ e GE para acelerar produção de ventiladores e máscaras. 24 mar. 2020. Disponível em: <https://forbes.com.br/last/2020/03/ford-se-une-a-3m-e-ge-para-acelerarproducao-de-ventiladores-e-mascaras/>. Acesso em: 22 abr. 2020.

FOUCAULT, M. Vigiar e punir: nascimento da prisão. Trad. Raquel Ramalhete. 20. Ed. Petrópolis: Vozes, 1999. Disponível em: < https://www.ufsj.edu.br/portal2repositorio/File/centrocultural/foucault_vigiar_punir.pdf > . Acesso em: 08 abr. 2020.

HC ON LINE. Covid-19: HCFMUSP recebe robôs de telepresença para atendimento em casos de isolamento. 01 abr. 2020. Disponível em: http://www.fm.usp.br/fmusp/noticias-em-destaque/covid19-hcfmusp-recebe-robos-de-telepresenca-para-atendimento-em-casos-de-isolamento Acesso em: 22 abr. 2020.

HURLEY, M. Supermax prison. Encyclopaedia Britannica, 07 de mar. de 2018. Disponível em <https://www.britannica.com/topic/supermax-prison>. Acesso em 22 de abr. de 2020. 
JORNAL VS. Geolocalização é ferramenta eficaz para monitorar aglomerações durante pandemia. 142 abr. 2020.2 Disponível <https://www.jornalvs.com.br/noticias/especial_coronavirus/2020/04/14/geolocalizacao-eferramenta-eficaz-para-monitorar-aglomeracoes-durante-pandemia.html>. Acesso em: 22 abr. 2020.

LYON, D; BAUMAN, Z. A vigilância líquida como pós-pan-panóptico. In: Vigilância Líquida. Trad. Carlos Alberto Medeiros. Rio de Janeiro: Zahar, 2014. Disponível em: < https://ciberativismoeguerra.files.wordpress.com/2016/09/vigilc3a2ncia-lc3adquida.pdf>. Acesso em: 08 abr. 2020.

MACEDO, R. O desafio da Medicina high-tech: saúde na palma da mão?. Sanarmed. Disponível em: $\quad$ https://www.sanarmed.com/o-desafio-da-medicina-high-tech-saude-na-palma-da-maocolunistas Acesso em: 22 abr. 2020.

PILAGALLO, S. Coronavírus: veja as tecnologias usadas para combater a pandemia. R7, 17 mar. 2020. Disponível em: <https://noticias.r7.com/tecnologia-e-ciencia/fotos/coronavirus-veja-astecnologias-usadas-para-combater-a-pandemia-17032020\#!/foto/1>. Acesso em: 22 abr. 2020.

PINHEIRO, V. Coronavírus: como a tecnologia é usada para combater a pandemia. Olhar Digital, 13 mar. 2020. Disponível em: <https://olhardigital.com.br/coronavirus/noticia/coronavirus-como-atecnologia-e-usada-para-combater-a-pandemia/98006>. Acesso em: 22 abr. 2020.

POSTER, M. The mode of information and postmodernity. In: The second media age. Cambridge: Polity, $1995 . \quad$ Disponível em:

https://books.google.com.br/books?id=mMFQDwAAQBAJ\&printsec=frontcover \&dq=\%22the+sec ond+media+age\%22+poster+1995\&hl=pt-PT\&sa=X\&ved=0ahUKEwjZgbC-

tIvpAhUXE7kGHcsAB5IQ6AEIKDAA\#v=onepage\&q\&f=false >. Acesso em: 08 abr. 2020.

ROCHA, L; PEREIRA, M. Tecnologia contra coronavírus prevê quais infectados terão complicações. Estado de Minas, 31 mar. 2020. Disponível em: <https://www.em.com.br/app/noticia/internacional/2020/03/31/interna_internacional,1134394/video -tecnologia-contra-coronavirus-preve-quais-infectados-terao-comp.shtml>. Acesso em: 22 abr. 2020.

SOARES, V. USP projeta ventilador pulmonar de baixo custo e rápida fabricação. Correio Braziliense, $\quad 062020.20$ abr. 202 Disponível <https://www.correiobraziliense.com.br/app/noticia/tecnologia/2020/04/06/interna tecnologia,8426 13/usp-projeta-ventilador-pulmonar-de-baixo-custo-e-rapida-fabricacao.shtml>. Acesso em: 22 abr. 2020.

SOUSA, J; OLIVEIRA, L. Banco de dados automatizados: a versão "ciberespacial" do panóptico na sociedade de controle. RJLB, Ano 6, n. 2. Lisboa: CIDP, 2020. Disponível em: < https://www.cidp.pt/revistas/rjlb/2020/2/2020_02_0613_0637.pdf >. Acesso em 13 abr. 2020.

WORLD HEALTH ORGANIZATION (WHO). Public statement for collaboration on Covid-19 vaccine development. 13 abr. 2020. Disponível em: <https://www.who.int/news-room/detail/13-042020-public-statement-for-collaboration-on-covid-19-vaccine-development>. Acesso em: 22 abr. 2020.

ZIMMER, M. O panóptico está superado?: estudo etnográfico sobre a vigilância eletrônica. Porto Alegre: UFRGS, 2009. Disponível em: < https://www.lume.ufrgs.br/handle/10183/15833>. Acesso em: 13 abr. 2020. 